FINAL REPORT

\title{
INTEGRATED VERTICAL AND OVERHEAD DECONTAMINATION (IVOD) SYSTEM
}

\author{
Principal Investigator: \\ M.A. Ebadian, Ph.D. \\ Florida International University \\ Collaborators: \\ L.E. Lagos \\ David Roelant \\ J. Varona \\ Ivo Kusijanovic \\ Rodrigue Ade
}

Prepared for:

U.S. Department of Energy

Office of Environmental Management

Office of Science and Technology

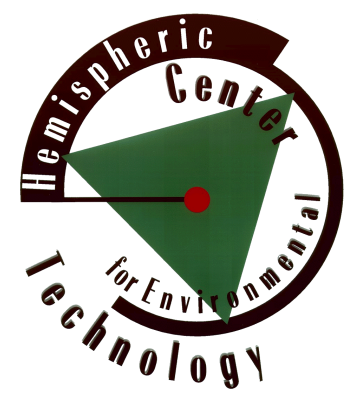




\section{DISCLAIMER}

This report was prepared as an account of work sponsored by an agency of the United States government. Neither the United States government nor any agency thereof, nor any of their employees, nor any of its contractors, subcontractors, nor their employees makes any warranty, express or implied, or assumes any legal liability or responsibility for the accuracy, completeness, or usefulness of any information, apparatus, product, or process disclosed, or represents that its use would not infringe upon privately owned rights. Reference herein to any specific commercial product, process, or service by trade name, trademark, manufacturer, or otherwise does not necessarily constitute or imply its endorsement, recommendation, or favoring by the United States government or any other agency thereof. The views and opinions of authors expressed herein do not necessarily state or reflect those of the United States government or any agency thereof. 


\title{
INTEGRATED VERTICAL AND OVERHEAD DECONTAMINATION (IVOD) SYSTEM
}

\author{
Principal Investigator \\ M.A. Ebadian, Ph.D. \\ Hemispheric Center for Environmental Technology \\ Florida International University \\ Miami, FL 33174

\section{Florida International University} \\ Collaborators \\ L.E. Lagos, David Roelant, J. Varona, Ivo Kusijanovic, and Rodrigue Ade \\ Hemispheric Center for Environmental Technology \\ Florida International University \\ Miami, FL 33174
}

January 2001

Prepared for

U.S. Department of Energy

Office of Environmental Management

Office of Science and Technology

U.S. Department of Energy

Under Grant No. DE-FG21-95EW55094 



\section{ACKNOWLEDGMENTS}

This report is based on work supported by the U.S. Department of Energy, Office of Environmental Management, Office of Science and Technology's Deactivation and Decommissioning Focus Area, National Energy Technology Laboratory. The Principal Investigator, the Florida International University (FIU) Collaborators, and students at FIU would like to thank Dr. Paul Hart, Robert Bedick, and Steve Bossart for providing the opportunity and support to work on this project. 



\section{TABLE OF CONTENTS}

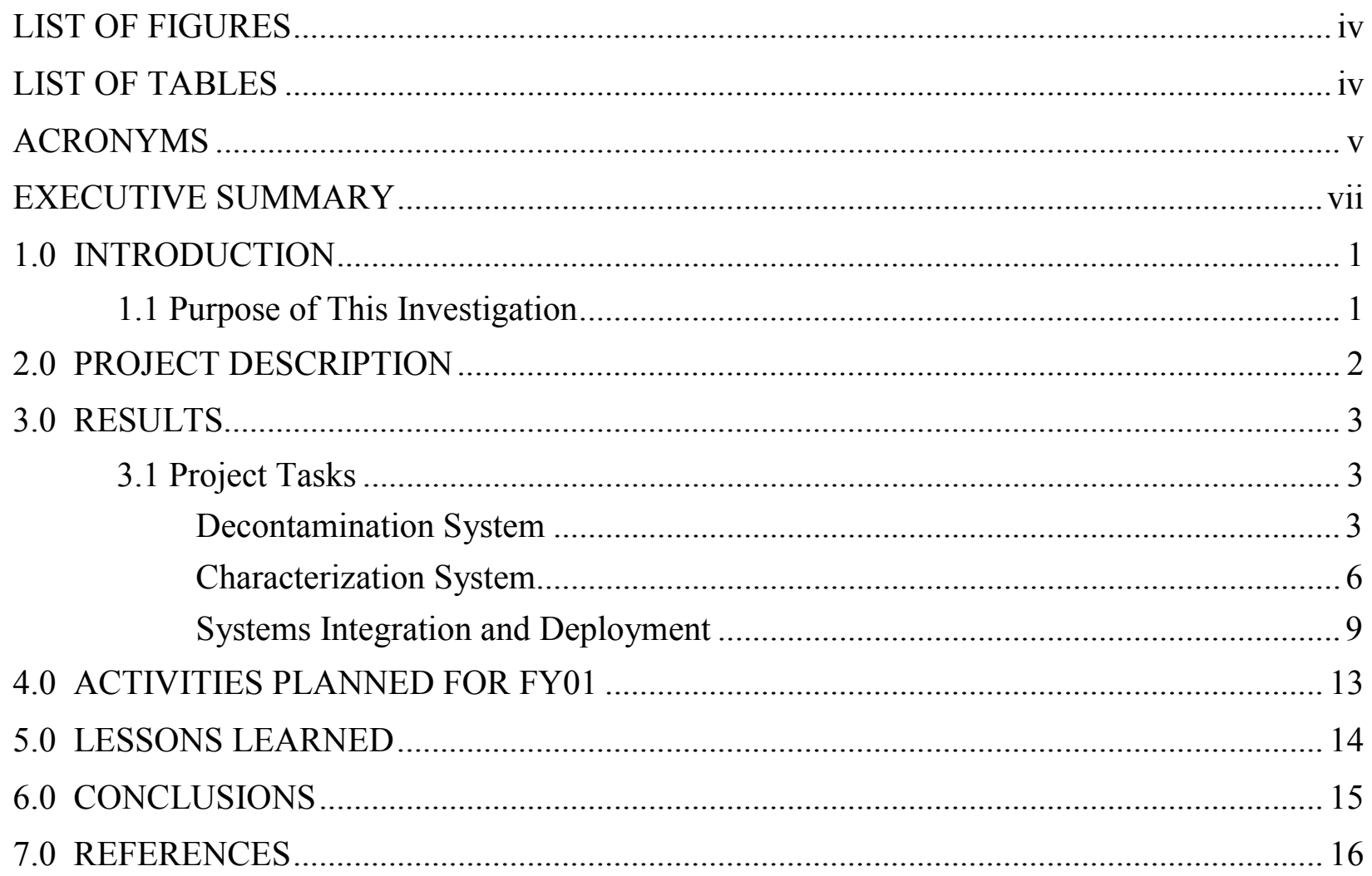

\section{APPENDIX: TEST PLAN FOR IVOD DEMOSTRATION AT RANCHO SECO FACILITY}




\section{LIST OF FIGURES}

Figure 1. Layout of Additional Components for the IVOD System........................................ 3

Figure 2. IVOD Current Configuration........................................................................ 5

Figure 3. Redzone Robotics' Field Test of IVOD Unit at FIU-HCET Test Site. ...................... 6

Figure 4. The SP-Series Sealed Gas Proportional Detectors Used for the IVOD System............ 7

Figure 5. Assembly Design for the SP-Series Sealed Gas Proportional Detector. ...................... 8

Figure 6. Graph Comparing Survey Data Collected at Rancho Seco Demonstration................... 9

Figure 7. Detectors Integrated into the IVOD's Suction Chambers. ........................................ 10

Figure 8. SP-Series Detectors Front Chamber Location....................................................... 10

Figure 9. SP-Series Detectors Rear Chamber Location....................................................... 11

\section{LIST OF TABLES}

Table 1. Technical Description of IVOD System ............................................................. 4 


\section{ACRONYMS}

CMST Characterization, Monitoring and Sensor Technologies

D\&D Deactivation and Decommissioning

DOE U.S. Department of Energy

FIU Florida International University

FIU-HCET Florida International University's Hemispheric Center for Environmental Technology

FY98 Fiscal Year 1998

FY99 Fiscal Year 1999

FY00 Fiscal Year 2000

FY01 Fiscal Year 2001

HCET Hemispheric Center for Environmental Technology

IVOD Integrated Vertical and Overhead Decontamination System

RAPIC Remedial Action Program Information Center

TAP Technology Assessment Program

TDID Technology Development, Integration and Deployment 



\section{EXECUTIVE SUMMARY}

The deactivation and decommissioning of 1200 buildings within the U.S. Department of EnergyOffice of Environmental Management complex will require the disposition of a large quantity of contaminated concrete and metal surfaces. It has been estimated that 23 million cubic meters of concrete and over 600,000 tons of metal will need disposition. The disposition of such large quantities of material presents difficulties in the area of decontamination and characterization. The final disposition of this large amount of material will take time and money as well as risk to the D\&D work force. A single automated system that would decontaminate and characterize surfaces in one step would not only reduce the schedule and decrease cost during D\&D operations but would also protect the D\&D workers from unnecessary exposures to contaminated surfaces.

This report summarizes the activities performed during FY00 and describes the planned activities for FY01. Accomplishments for FY00 include the following:

- Development and field-testing of characterization system

- Completion of Title III design of deployment platform and decontamination unit

- In-house testing of deployment platform and decontamination unit

- Completion of system integration design

- Identification of deployment site

- Completion of test plan document for deployment of IVOD at Rancho Seco nuclear power facility. 



\subsection{INTRODUCTION}

\subsection{PURPOSE OF THIS INVESTIGATION}

The overall objective of this project is to fabricate and test an innovative technology for the purpose of characterizing and decontaminating vertical and overhead structures and to transfer this technology to industry for use in reducing the cost to perform decontamination operations. The sub-objectives required to meet the overall objective include the following:

- Design and fabricate a characterization system for overhead and vertical applications.

- Design and fabricate a decontamination system for overhead and vertical applications.

- Integrate and assess the system for commercial application.

- Transfer the system to industry for use throughout the DOE complex.

- Make the entire system self-contained and ready for deployment.

- Demonstrate the system at other DOE or commercial nuclear sites. Potentially, this technology may be tested at a large-scale demonstration and deployment project (LSDDP. 


\subsection{PROJECT DESCRIPTION}

The purpose of this project was to define and develop a cost-effective integrated system with which to characterize and decontaminate concrete and metal surfaces from walls and ceilings. The following tasks were scheduled for completion during FY00.

\section{Decontamination System}

Task 1. Design of Additional System Components

Task 2. Title III Design

Task 3. Operations

Task 4. Close-Out

\section{Characterization System}

Task 1. Development of Characterization System Design

Task 2. Test Site Design and Development

Task 3. Fabrication of Characterization System

Task 4. Characterization System Test and Design Confirmation

\section{Systems Integration and Deployment}

Task 1. Integrate Decontamination and Characterization Systems

Task 2. Development of Maintenance and Operations Manual

Task 3. In-House Field Testing of Integrated System

Task 4. Field Implementation at a Selected DOE Site 


\subsection{RESULTS}

The 12 tasks presented in Section 2 "Project Description" and in the FY00 Project Technical Plan (PTP) are described below. The italicized text indicates the task description presented in the FY00 PTP. The results of each task and any deviations are presented in the paragraphs that follow. The project tasks have been grouped into three categories: Decontamination System, Characterization System, and Systems Integration and Deployment, emphasizing the three major areas of research conducted in FY00.

\subsection{PROJECT TASKS}

\section{Decontamination System}

\section{Task 1. Design of Additional System Components}

The integrated system will be made field-deployable and transportable. Additional equipment and components will be designed and/or purchased in order to achieve portability. A Strong Tight Container, a flat bed trailer, and a trailer-mounted air compressor will be procured. These items will provide the necessary transportability and utility requirements for the system.

The additional components were identified and designed to make the IVOD system completely field deployable and transportable. Vendors were consulted and "best in its class" equipment was identified. The conceptual component integration diagram is presented in Figure 1 below.

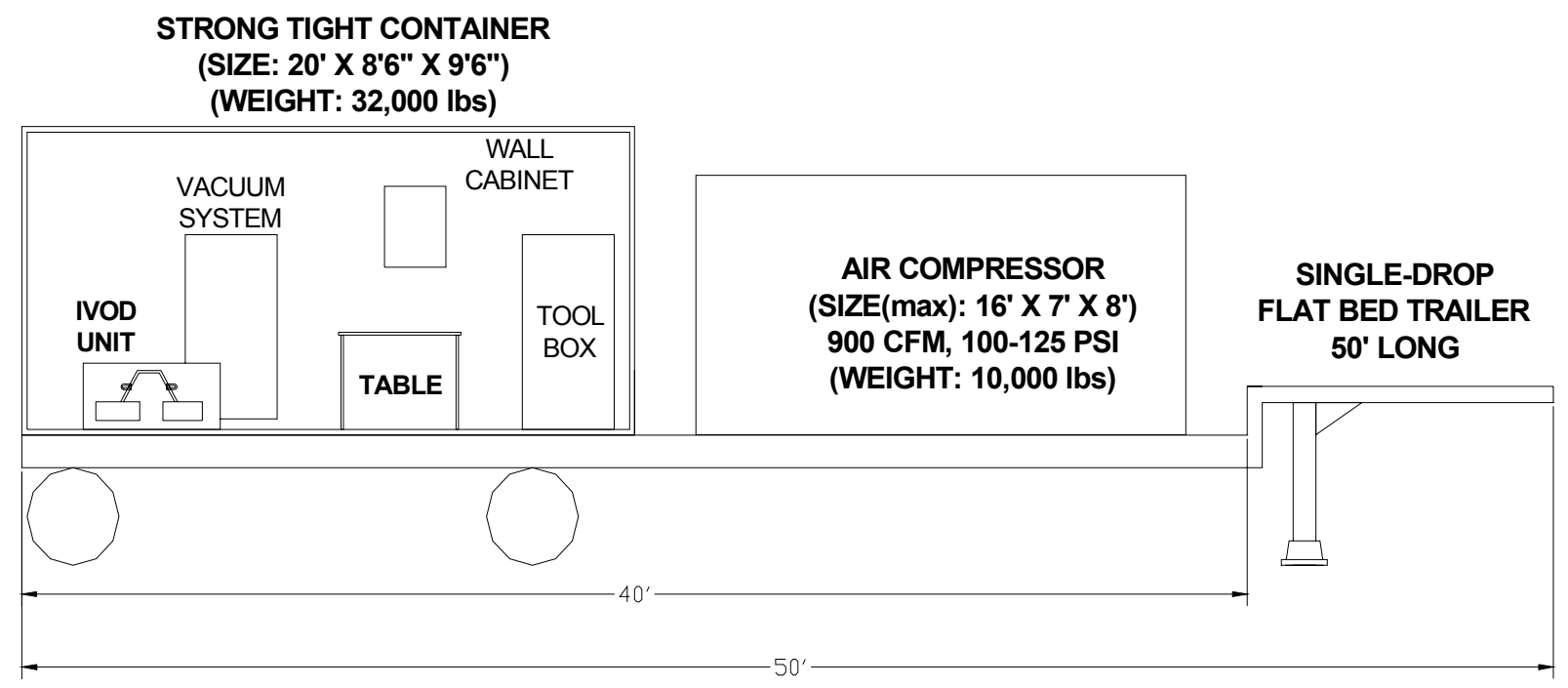

Figure 1. Layout of Additional Components for the IVOD System. 
Procurement specification packages were prepared for all the additional system components identified. The packages for each component include the technical requirements in the form of specifications, the condition set for the vendor to meet followed by quotes provided by at least three vendors, and the respective contact information.

Due to a shortage of funds under the project, the Strong Tight Container and the flat bed trailer could not be procured during FY00. However, the requisition process for the trailer-mounted air compressor was initiated as this was considered the most necessary of all the additional system components. The procurement of the other components will be considered during FY01.

\section{Task 2. Title III Design}

FIU-HCET will monitor the fabrication of the decontamination and deployment systems to ensure that the specifications and final design drawings are being followed.

As part of Title III Design, the different subsystems of the IVOD unit were identified through the design and fabrication process carried out by Redzone Robotics. Title III design review was conducted at the Redzone Robotics facility in Pittsburgh. The IVOD unit subsystems along with its major components are listed in Table 1 below.

Table 1

Technical Description of IVOD System

\begin{tabular}{|l|l|}
\hline \multicolumn{1}{|c|}{ IVOD Subsystem } & \multicolumn{1}{c|}{ Component Description } \\
\hline Mobility platform & Wheels, Steering, Suspension \\
\hline Drive system & $\begin{array}{l}\text { Motors, Gearing, Attachment system, Chambers, Seals, Attachment } \\
\text { vacuum generator }\end{array}$ \\
\hline Tooling & $\begin{array}{l}\text { Cutting heads, Drive shaft, Tool motor, Mounting frame, } \\
\text { Raise/lower/depth control }\end{array}$ \\
\hline Debris removal system & $\begin{array}{l}\text { Vacuum system, Filter system, Fall protection system, Self-contained } \\
\text { retractable lifelines, Fastening mechanism }\end{array}$ \\
\hline Power distribution and control unit & Filter regulators, Air compressor, 120v source \\
\hline Operator control station & Integrated portable control box, tether \\
\hline
\end{tabular}

The IVOD unit was assembled and pre-tested at the Redzone Robotics facility; Figure 2 details the IVOD in its current configuration. Figure 2 shows the three-chamber modular design adopted for this technology. The current design has two suction chambers and one decontamination chamber located in the middle of the mobile platform assembly. 

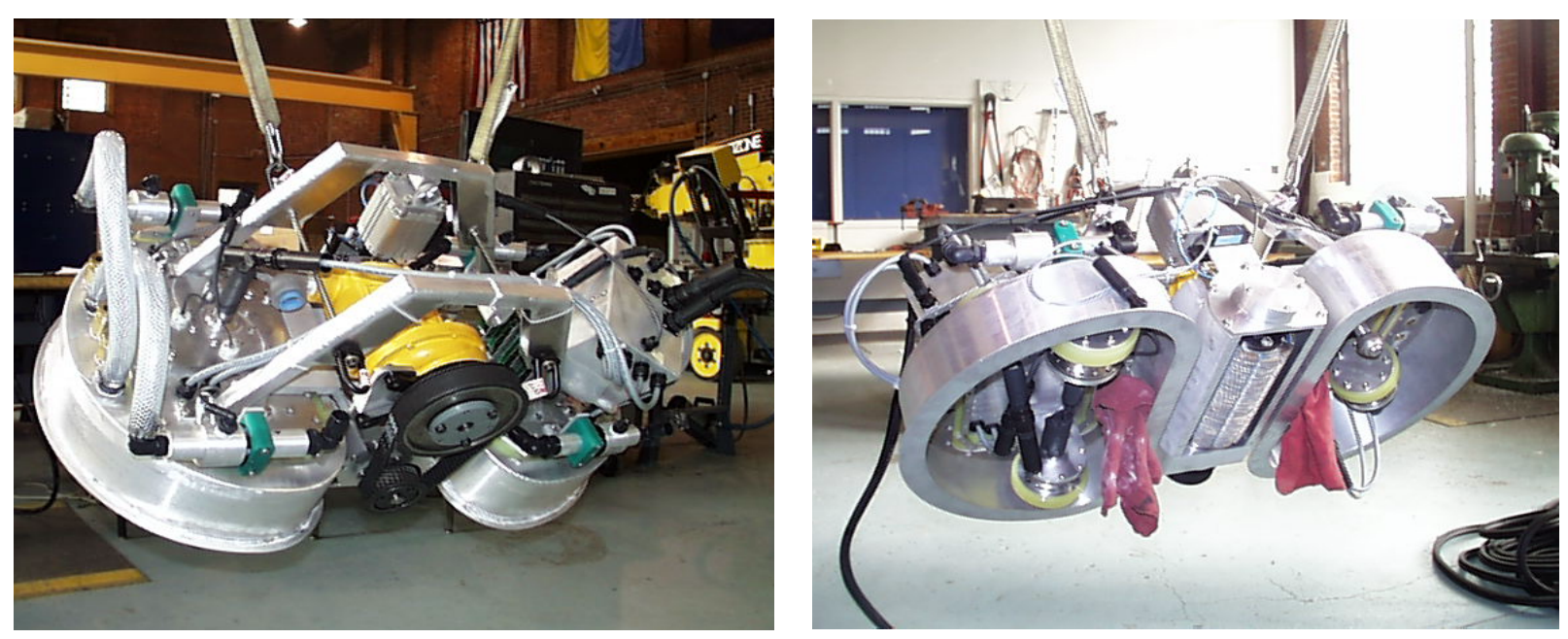

Figure 2. IVOD Current Configuration.

\section{Task 3. Operations}

The decontamination system will be field-tested at FIU-HCET's test site. The D\&D assessment group will conduct this test. This test will consist of a combination of concrete walls, ceilings, and floors as well as coated and rusted metal surfaces. The subcontractor will develop a detailed operations and maintenance manual. Remediation service companies will be invited when the system is tested to solicit input and determine potential technology transfer partners. In addition, the International Union of Operating Engineers will be invited to provide input on the Health and Safety aspect of the operation.

The IVOD system was field-tested at FIU-HCET's test site during March 2000. Redzone Robotics performed the test demonstration at FIU-HCET for assessment and evaluation by FIUHCET personnel. FIU-HCET's TAP personnel recorded observations during the field-test.

Though the IVOD unit did cut concrete on floor and wall surfaces, the rapid deterioration of the seals and the periodic failure of the filtration system prevented a full performance test. However, the TAP personnel at FIU-HCET collected data, just enough to roughly estimate the area of each pass of the IVOD unit, production rate, and depth of decontamination. The IVOD unit was observed to clean the concrete floors and walls with each pass that was $1 \mathrm{ft}$ wide, and the length of each pass ranged between 4-6 ft. The production rate as deduced from this demonstration was estimated at $3.6 \mathrm{ft}^{2} / \mathrm{min}$, with a depth of removal at $1 / 8^{\text {th }}$ inch. 

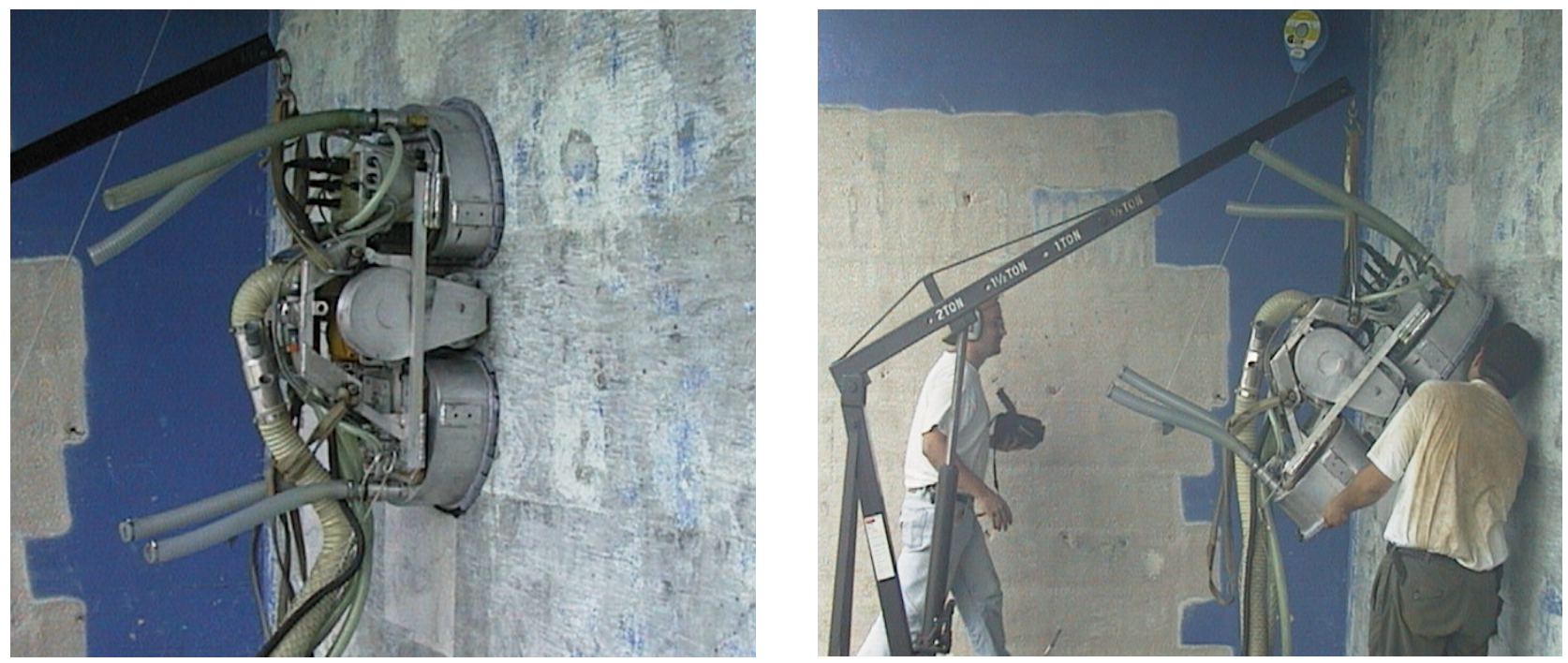

Figure 3. Redzone Robotics' Field Test of IVOD Unit at FIU-HCET Test Site.

\section{Task 4. Close-Out}

Upon successful field-testing, two FIU-HCET employees will be trained to operate and maintain the system.

The field-testing of the system at FIU-HCET test site was not successful. A number of problems were identified, and the field-test was terminated. Section 5 "Lessons Learned" of this report identifies and discusses some of the technical difficulties encountered by Redzone during this field-test. Based on the results from this test, Redzone was not able to train FIU-HCET personnel in the operation and maintenance of this system.

\section{Characterization System}

\section{Task 1. Development of Characterization System Design}

A complete characterization system, customized for implementation within the decontamination platform, will be developed. Specific details of design will include adaptation of existing radiological characterization components, identification of additional commercial components, and design of required new components.

From the short-list of available characterization technologies prepared during FY99, the SPSeries Large Area Sealed Gas Proportional Detector was selected as the characterization technology for potential integration into the IVOD system. During FY00, the TDID and the CMST groups at FIU-HCET collaborated to design, fabricate, and integrate the SP-series sealed gas proportional detector for integration into the IVOD unit. These gas proportional detectors are filled with Argon gas that when exposed to gamma radiation separates the Argon atoms into a pair of ions with positive and negative charges. The negative charged particle can be transformed into a pulse or current signal read by the electronic signal processor and fed into the system electronic package. Power to the counting system is fed through a computer controller to the 
detectors. The counts from the detector are recorded on an on-site computer and displayed on a monitor to measure the progress of the decontamination. The count-rate data is displayed on a flat-screen monitor mounted in front of the operator. The count-rates carry a color-coded bar on the display showing red for contaminated and green for clean. The electronics components supporting the detectors consist of a high-voltage pulse detector, a precision signal counter module, a computing module, and a display panel. Each module is controlled by a custom software application developed by FIU-HCET personnel.

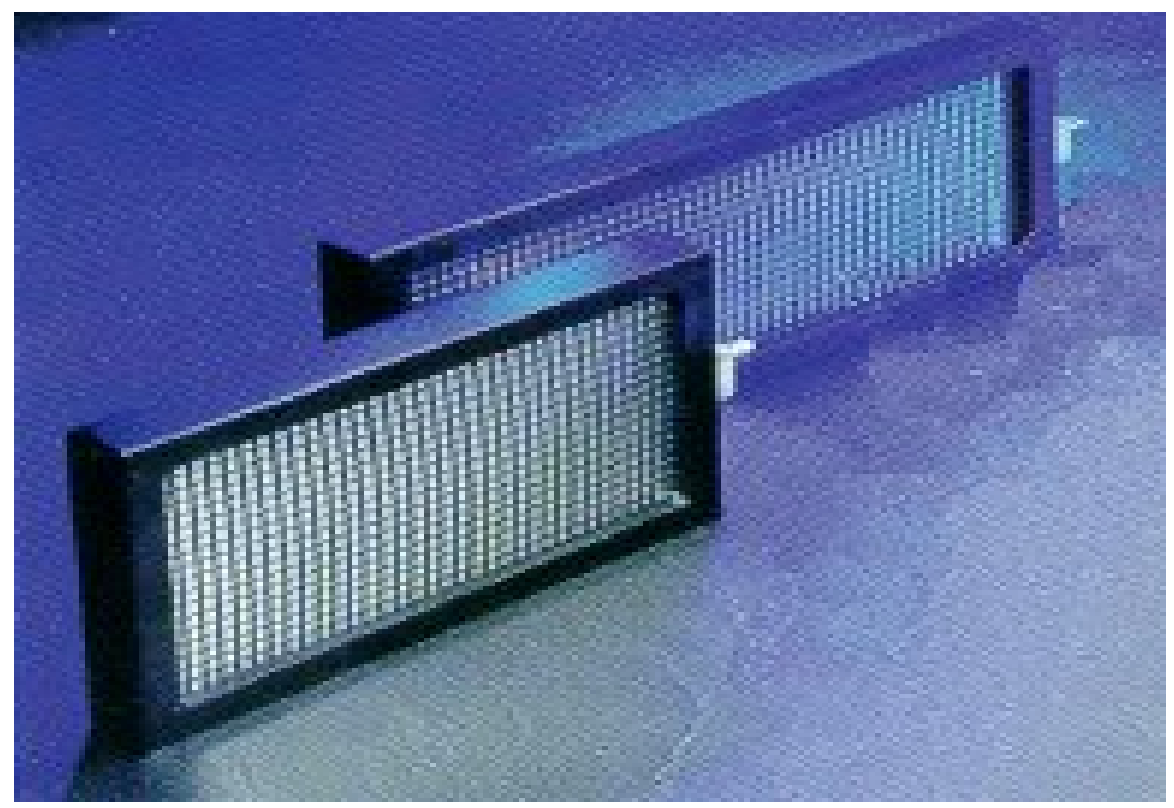

Figure 4. The SP-Series Sealed Gas Proportional Detectors Used for the IVOD System.

\section{Task 2. Test Site Design and Development}

FIU-HCET will design and fabricate a test site for the evaluation and deployment of the characterization system integrated with the decontamination and deployment mechanism. The area will contain Cs-137 radiological sources embedded in concrete floors and walls.

A test site area was designed in order to test the characterization system at the FIU-HCET test facility; the concept was to use Cs-137 radiation sources as the contamination to be detected on concrete floors and walls. A design package for this test site was developed and was submitted for internal FIU-HCET peer review. However, this test bay was not developed based on the opportunity given to FIU-HCET to be able to test this detection system as part of the online measurement decontamination system demonstrated at Rancho Seco nuclear facility in May 2000. The characterization system development and design was made modular so that this system could be moved between multiple decontamination technologies and deployment platforms. Since this test at Rancho Seco was going to be conducted on real contaminated surfaces, the test site development at FIU-HCET was cancelled. 


\section{Task 3. Fabrication of Characterization System}

The characterization system, complete with sensors, sensor housing, and support structures, control electronics, data communication subsystem, and human interface, will be constructed according to design.

TDID/CMST engineers generated a design package in order to assemble the gas proportional detectors onto the IVOD unit. A thin Mylar layer was used to cover the detector window for protection. A 1/64" Kevlar/Nitrile rubber gasket was placed between the detector active area and the contaminated surface to provide a pressure seal while still allowing nearly all beta and gamma radiation into the detector. An electronic package and computer programs were developed to process the signal and graphically display the counts per second onto a computer screen. A specially designed keyboard was incorporated onto this package to allow the operator to initialize and start up the system. A hard drive allowed for the collection and storage of data during the characterization process. This data was made retrievable by means of a floppy diskette. The entire design was made modular so that it can be adapted to various decontamination technologies.
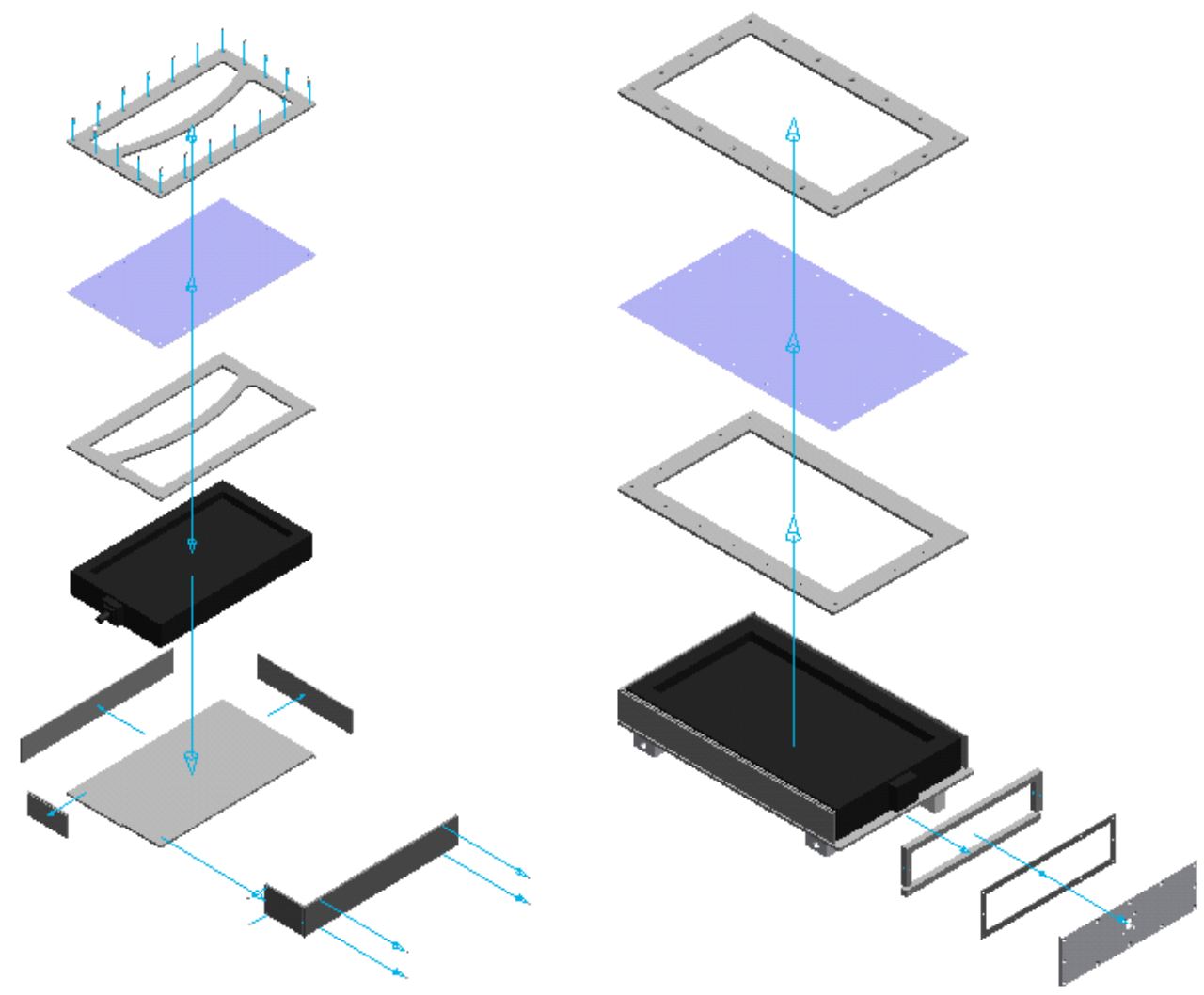

Figure 5. Assembly Design for the SP-Series Sealed Gas Proportional Detector. 


\section{Task 4. Characterization System Test and Design Confirmation}

The characterization system will be calibrated and tested as per design criteria. Performance discrepancies will be remedied, and the system will be prepared for integration with the decontamination system.

The SP-Series Sealed Gas Proportional Detectors were fully tested in the FIU-HCET laboratory using Cs-137 radiation sources. In addition, the characterization system was assembled at FIUHCET and field-tested at Rancho Seco nuclear power facility in the form of the characterization technology integrated into the online decontamination system. The data obtained from the survey conducted by the characterization system was compared to data collected from a survey conducted by Rancho Seco Health Physics (HP) personnel using a handheld frisker. The results are plotted as a graph, which is displayed in Figure 6.

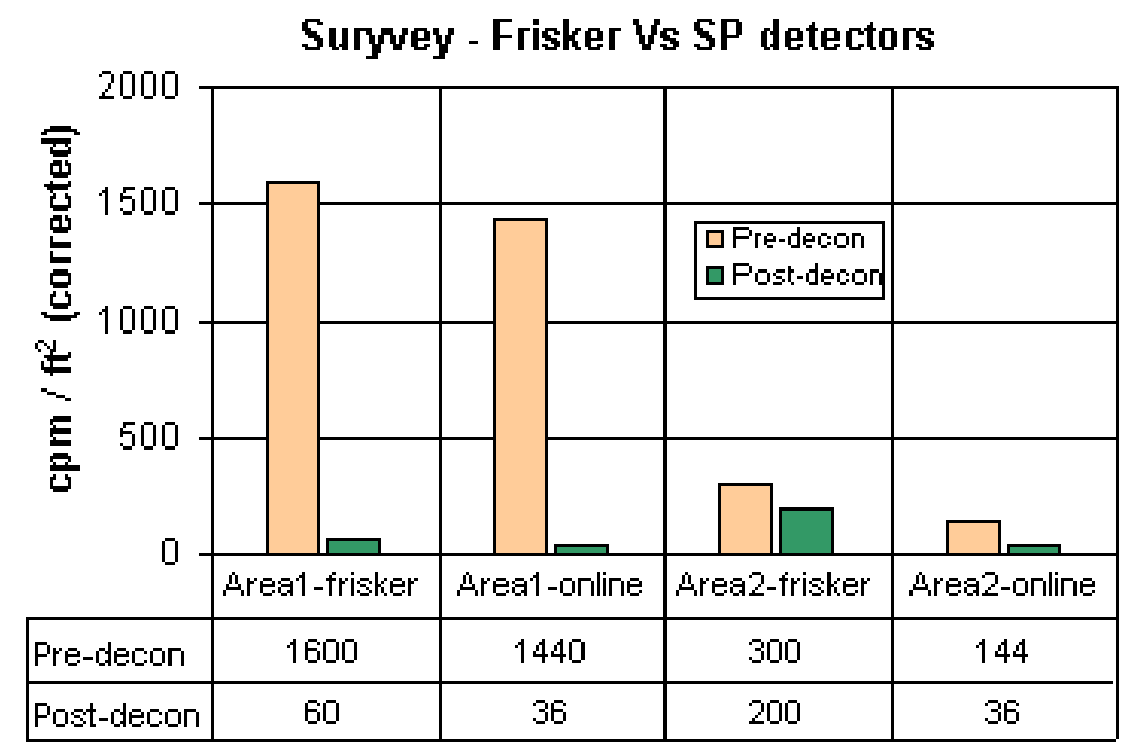

Figure 6. Graph Comparing Survey Data Collected at Rancho Seco Demonstration.

\section{Systems Integration and Deployment}

\section{Task 1. Integrate Decontamination and Characterization Systems}

The decontamination and characterization systems will be integrated into one complete deployment platform containing a decontamination tool, characterization instruments, and a waste collection system. Prior to field implementation at a DOE site, the systems will be tested to ensure all material handling, power, and system layout issues are resolved to ensure that the system operates as an integrated system.

The decontamination and characterization systems were integrated by placing the two SP-series sealed gas proportional detectors into the front and the rear chambers of the IVOD unit, 
respectively. The detectors were installed inside the IVOD system chambers so as to minimize the IVOD size and maximize its maneuverability, as indicated in Figure 7. The directional wheel in the front chamber prevented the front sensor from being completely enclosed inside the front chamber. The detectors were installed in an airtight enclosure to protect them from the 0.3 atmosphere pressures inside the IVOD chambers (as detectors will fail at pressures below 0.3 atmospheres).

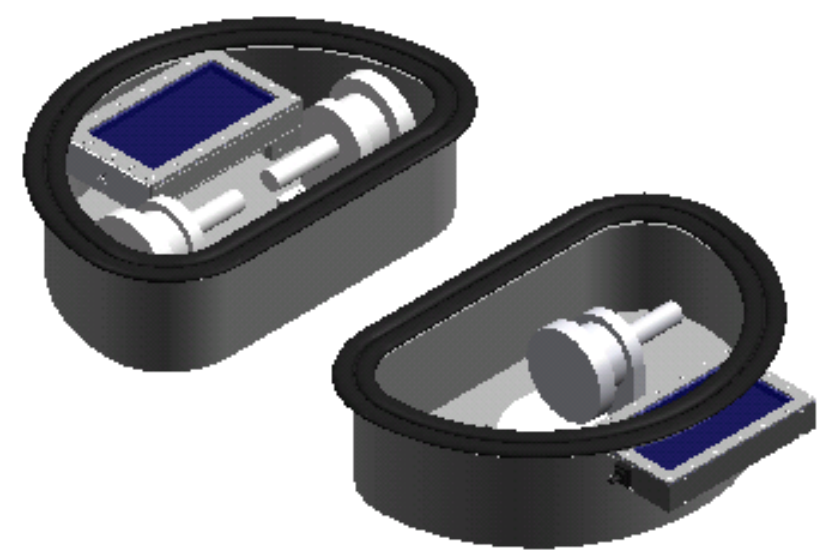

Figure 7. Detectors Integrated into the IVOD's Suction Chambers.
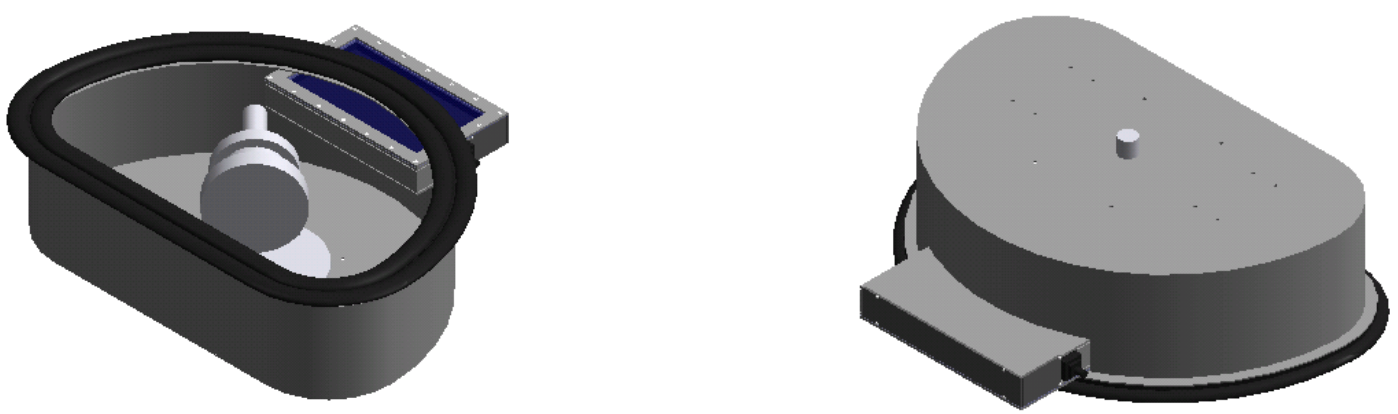

Figure 8. SP-Series Detectors Front Chamber Location. 

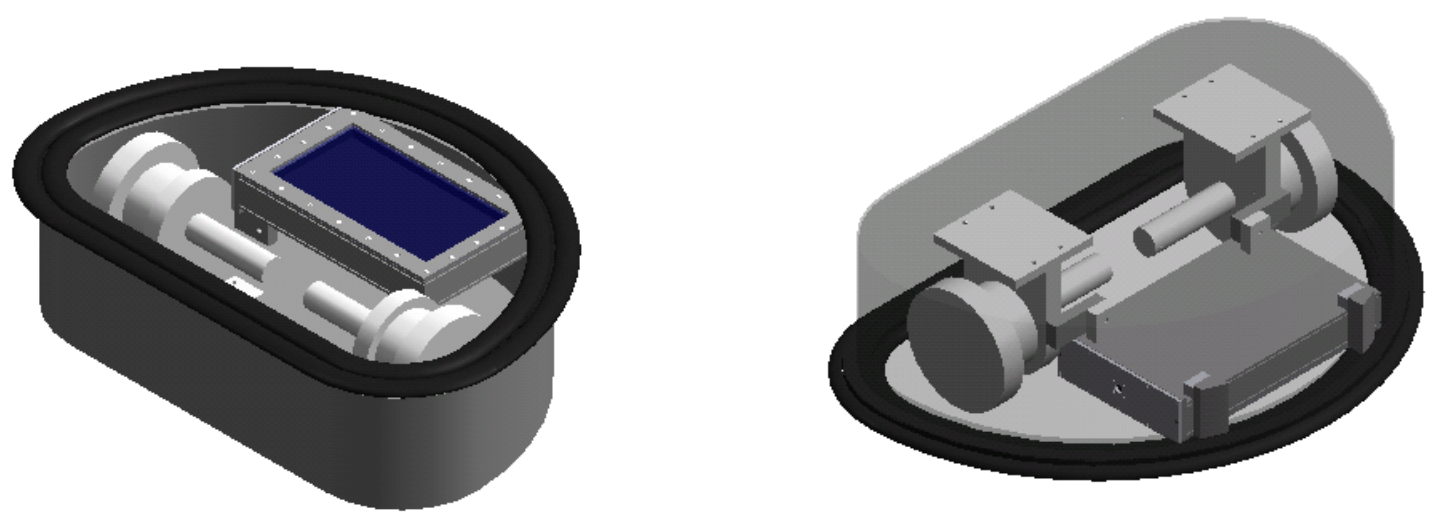

Figure 9. SP-Series Detectors Rear Chamber Location.

\section{Task 2. Development of Maintenance and Operations Manual}

FIU-HCET will develop an integrated Maintenance and Operations Manual. This manual will contain the necessary information to maintain and operate this equipment.

This task was not $100 \%$ completed based on not having the equipment available and in working conditions at FIU-HCET. A draft copy of this document was generated but not completed. Once the system is completed and operational, this document can be completed.

\section{Task 3. In-House Field-Testing of Integrated System}

A field-test will be conducted at FIU-HCET's Test Facility. This test will evaluate the entire integrated system including the shaving of concrete areas containing embedded Cs-137 radiological sources. Data will be collected in the areas of performance, cost, maintenance, and health and safety.

This task was not accomplished, based on Redzone's delays and then final conclusions/recommendation that Redzone could not deliver a working system that would perform as per Redzone's original proposal and the FIU-HCET specification document. At this point, conversation has been conducted with Redzone to identify a path forward for this technology. Several scenarios have been identified and discussed. As an immediate task, FIUHCET will sort out procurement and property control issues and mark all equipment with FIU's property control tags. In the interim, the equipment will reside at Redzone facility in Pittsburgh, PA, until a definite path is reached.

\section{Task 4. Field Implementation at a Selected DOE Site}

With the help of the DOE DDFA, a remediation project will be initiated on a minimum number of concrete and metal surfaces to operate the system at a selected site. Remediation service companies will be invited when the system is tested to solicit input and finalize potential technology transfer partners. 
A deployment site was identified during FY00; the site identified was the Rancho Seco utility site in Rancho Seco, CA. This site was selected with the help of the Electric Power Research Institute (EPRI) and the Sacramento Municipal Utility District (SMUD). A tentative deployment site was scheduled for FY00, and a deployment test plan was developed (see Appendix B). Unfortunately, this task has been rescheduled for FY01 since the equipment was not ready for deployment in FY00. In addition, a survey was conducted in FY00 to identify additional utility sites that may have a use for this system. 


\subsection{ACTIVITIES PLANNED FOR FY01}

This is the last year of this project. A complete working system was expected by the end of FY00, but due to delays from Redzone the final completed unit has not been developed. During FY01 FIU-HCET's TDID Program will continue working with Redzone Robotics in trying to complete the system development and providing opportunities for demonstration and deployment for this system. 


\subsection{LESSONS LEARNED}

A number of lessons learned were identified during the development process of this technology; some were beyond FIU-HCET's control. A lessons learned list was compiled trying to capture some of the problems faced during the demonstration of this unit at FIU-HCET. With help from Redzone Robotics, FIU-HCET identified several flaws with the system. Redzone Robotics proposed a list of future actions. The various problems identified through the demonstration include the following aspects:

1. The debris removal vacuum system did not perform in combination with the cutter head. The filters rapidly clogged and imploded, causing release of dust into the work area, an unacceptable failure. The pump did not produce enough vacuum flow to handle the flows from the attachment system and the debris removal system, weakening the attachment vacuum.

2. The frame flexes when the crawler drives under the attachment vacuum. The flexing derives from the 2-chamber A-frame geometry of the system and the tricycle configuration of the wheels. This flexing causes the chambers to cant, with an intermittent loss of seal and unacceptable attachment reliability. Without altering the frame and wheel geometries, the method of correction is frame stiffening, which conflicts with other elements of the tightly integrated system. The frame-stiffening members reduced the serviceability and interchangeability of the tooling. The flexing also produced an uneven cut - deeper on the side.

3. While the general system configuration - two D-shaped attachment chambers straddling the cutter head, with drive and steering wheels internal to the chambers - yielded a low edge margin, it left large head and tail margins. The system had limited steering agility (especially in light of the frame flexing) with consequent reduced productivity. The configuration did not offer convenient spaces for mounting pre- and post-operation sensors without substantially greater head margins.

4. Several seals were tested throughout the development process, in search of optimization across four parameters - efficiency of seal (strength of vacuum pump necessary to hold to surface), low friction when driving, maintenance of seal on uneven surfaces (dynamic conformance), and wear resistance (required frequency of change-out). Appendix C presents a table of test results. No design satisfied all the constraints. The next design iteration will be based on more detailed specifications. A relaxation of any one constraint will allow for many more satisfactory designs. Most importantly, the rough surface of the FIU/HCET test facility destroyed the seals rapidly. If this surface is typical of expected applications, the system will need a more robust seal, which cannot be incorporated given the current design configuration. 


\subsection{CONCLUSIONS}

Design, procurement, and fabrication of the characterization and decontamination was completed during FY00. In addition, two field-tests were conducted on the two major subcomponents of this technology. The first field-test was conducted at the FIU-HCET facility which including the testing of the mobile deployment platform and the decontamination technology. Several deficiencies in the system design and performance were identified, but, nevertheless, the system proved to be a viable potential solution to many decontamination problems sets throughout the complex.

The second test consisted of the testing of the characterization system at Rancho Seco. This demonstration proved the effectiveness of having an integrated decontamination and characterization system. Additional work needs to be identified, and a path forward needs to be established in order to complete the system integration and perform a field-test. These issues will be addressed during FY01 under the TDID Program. 


\subsection{REFERENCES}

1. Baseline Environmental Management Report (BEMR), a document prepared by DOE. Contaminated Concrete: Occurrence and Emerging Technologies for DOE Decontamination, a document prepared by DOE.

2. Ebadian, M.A., Lagos, L.E., August 1997, Analysis of Potential Surface Blasting Decontamination Technologies for Structural Steel, Final Report, Hemispheric Center for Environmental Technology (HCET), Florida International University, Miami, FL.

3. Ebadian, M.A., Lagos, L.E., November 1997a, Evaluation of Coating Removal of Aggressive Surface Removal Technologies Applied to Concrete Walls, Brick Walls, and Concrete Ceilings, Final Report, Hemispheric Center for Environmental Technology (HCET), Florida International University, Miami, FL.

4. Ebadian, M.A., Lagos, L.E., November 1997b, Analysis of Potential Concrete Floor Decontamination Technologies, Final Report, Hemispheric Center for Environmental Technology (HCET), Florida International University, Miami, FL.

5. Market Assessment Decontamination of Radiologically Contaminated Concrete, a report developed by the Global Environmental \& Technology Foundation.

U.S. Department of Energy, 1990, Radiation Protection of the Public and the Environment, DOE Order 5400.5, Office of Environment, Safety and Health, Washington, D.C.

6. U.S. Department of Energy, 1996a, Decontamination and Decommissioning Focus Area Results of the National Needs Assessment, U.S. Department of Energy-Office of Environmental Management, Washington, D.C.

7. U.S. Department of Energy, 1996b, Decontamination and Decommissioning Focus Area Technology Summary, DOE/RL-93-0, U.S. Department of Energy-Office of Environmental Management, Washington, D.C.

8. U.S. Nuclear Regulatory Commission, 1982, Regulatory Guide, Termination of Operating Licenses for Nuclear Reactors, Regulatory Guide 1.86, Washington, D.C. 


\section{DEMONSTRATION TEST PLAN FOR IVOD DEMONSTRATION AT RANCHO SECO FACILITY}





\title{
IVOD Decontamination System
}

\author{
TEST PLAN
}

\subsection{Introduction}

The National Energy Technology Laboratory (NETL) D\&D Focus Area, EPRI, FIU, Argonne National Laboratory, and several utilities have joined together in signing a Memorandum of Understanding for the purpose of sharing information relative to the application of commercial technologies to the processes involved in the decontamination and decommissioning (D\&D) of nuclear facilities. Performing technology demonstrations at sites where D\&D is taking place develops the information. The results of these demonstrations are presented in formal reports that are available to signers of the MOU, NETL and EPRI program participants.

Rancho Seco is a 913 MWe Babcock \& Wilcox designed nuclear power plant owned by the Sacramento Municipal Utility District (SMUD). The plant began commercial operation in 1975 and was shut down in June 1989 as a result of a voter referendum. Because there was only a minimal decommissioning fund, it was decided to place the plant in a SAFSTOR condition for an extended period until 2008 when sufficient funds to pay for the dismantlement would be available.

In 1991 the decision was made to place the spent fuel in dry storage by constructing an Independent Spent Fuel Storage Installation (ISFSI) on-site. The fuel is expected to be in storage by the end of 2000. When the Envirocare facility became available for the disposal of very low activity waste at a significant cost saving relative to the D\&D cost estimate assumed disposal costs, the decision to dismantle the turbine building was made. This allowed use of the on-site staff while preparations for the fuel movement proceeded. This project began in 1997. The dismantling of the turbine building is now complete, leaving several areas of contaminated concrete.

The technology selected for this demonstration is the IVOD, which is a concrete shaving machine mounted on a robotic wall walker. The system is being developed by Florida International University's Hemispheric Center for Environmental Technology (FIUHCET). The system is designed to remove surface contamination from concrete walls and ceilings.

\section{$1.1 \quad$ Purpose}

The purpose of this demonstration is to develop data that will allow potential users of the measuring technology to make evaluative judgments concerning its application to specific D\&D needs. Both EPRI and DOE/NETL reports will be generated containing the data gathered during the demonstration. The data will include information related to

- The operation of the systems

- The costs of operation and procurement, lease or use

- Data on the results of the actual concrete cleaning activities

- Data on the accuracy and use of the online measuring system 
- Training and procedural requirements and more.

\subsection{Scope}

The scope of the demonstration will include the full range of operations for the equipment to be demonstrated. Rancho Seco personnel will be trained to operate the monitoring and cleaning equipment. The demonstration will include the following:

- The preoperational work required for using the equipment at the SMUD site, including any training requirements, special operational procedures, safety evaluations, and other site preparations

- The time and level of effort for mobilization prior to use and the demobilization following the use, including radiation surveys, equipment decontamination, consumables disposal, and waste disposal

- The ability to handle uneven and/or rough surfaces including cracks and expansion joints

- The support staff requirements to support the activity

- The effectiveness of the wall shaving system

- The effectiveness of the dust removal system

- The ability to determine the presence and/or absence of contamination at very low levels defined to be not detectable by a standard survey using a handheld pancake survey instrument

- Volume reduction through online measurement

- Accuracy of the measurement system at low contamination levels.

\subsection{Organizational Structure and Key Personnel}

Table 1.

Key personnel involved in the demonstration of the FIU Online Decontamination Measuring System

\begin{tabular}{|l|l|l|l|}
\hline Key Project Personnel & Name & Phone Number & E-mail \\
\hline Project Specific Title & Einar Ronningen & $916-732-4817$ & eronnin@smud.org \\
\hline SMUD Project Manager & Bob Snyder & $916-732-4814$ & \\
\hline SMUD Project Lead & Mike Steinbacher & $916-732-4863$ & \\
\hline SMUD Health Physics & Steve Porterfield & $916-732-4867$ & sporter@smud.org \\
\hline SMUD Waste Management & Leonel E. Lagos & $305-348-1810$ & leonel@eng.fiu.edu \\
\hline FIU Project Lead & Dave Roelant & $305-348-6625$ & roelant@eng.fiu.edu \\
\hline FIU Project Manager - CMST & Jose Varona & $305-348-6653$ & jvarona@eng.fiu.edu \\
\hline FIU Project Manager - D\&D & Rodrique Ade & $305-348-2322$ & rade@eng.fiu.edu \\
\hline FIU Project Manager - CMST & Nelson Rekos & $304-285-4066$ & nelson.rekos@netl.gov \\
\hline NETL Manager & Robert C. Thomas & $650-855-2047$ & rothomas@epri.com \\
\hline EPRI Representative & Kenneth D. Kok, & $480-671-5850$ & Ken069@msn.com \\
\hline NETL Representative & PE & \\
\hline
\end{tabular}




\subsection{Field Demonstration Program}

The demonstration program will be a test of the equipment in a realistic setting, in this case, the turbine building area of the Rancho Seco nuclear power station. All of the equipment has been removed from the test area, leaving bare concrete that has areas of low-level contamination. The levels may be as low as 20-40 cpm above background determined using a standard pancake survey instrument.

\subsection{Demonstration Area Description}

The location will be one or more of several areas in the turbine building, grade level, and/or the condenser pit. These possible locations include a couple of different types of flat surfaces, a variety of vertical surfaces, and a potential for a surface of about 45 degree angle, if desired. Surface conditions (horizontal) range from smooth, level surfaces to uneven surfaces with exposed rebar. Vertical and angled surfaces are smooth, level. Both contaminated and uncontaminated surfaces are available in these areas. In general, specific contaminated areas do not exceed 100-200 square feet.

Contamination levels run about $2000-3000 \mathrm{dpm} / 100 \mathrm{~cm}^{2}$ with localized areas up to $10,000 \mathrm{dpm} / 100 \mathrm{~cm}^{2}$. This contamination is fixed. The levels of contamination were determined using a pancake tube survey. The depth of the contamination is not known, but based on similar areas it is not expected to exceed the $1 / 8$ " $-1 / 4$ " range $(3-6 \mathrm{~mm})$.

\section{$2.2 \quad$ IVOD System Operation}

The detailed operating procedures for the IVOD are contained in the system manual. The manual for the detection system contains the instructions for that system. These instructions provide the basis for the following general discussion.

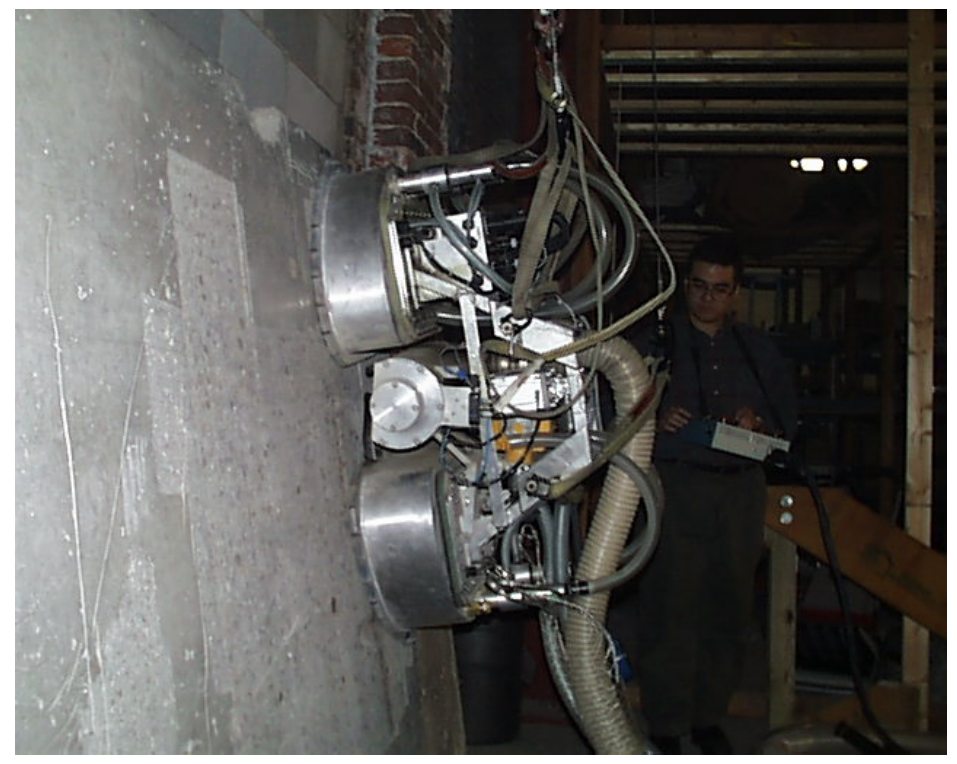

Figure 1 The IVOD system is used to decontaminate walls and ceilings. 
The IVOD consists of a robotic system specially designed by Redstone Robotics that acts as a transport and positioning device for a Marcrist wall shaving unit. The positioning device consists of two feet that provide a vacuum attachment to a wall or ceiling. Each foot is able to support the total weight of the device, allowing it to "walk" over a smooth surface moving one foot at a time. A safety harness is attached to the equipment to keep it suspended in case of a vacuum failure.

The wall shaver unit will reliably provide high production shaving utilizing 100 interlocking diamond blades. The system consists of an electric hydraulic power unit, shaver control panel, and shaver mast attached to the tool carrier. The mast is 2.2 meters long with three sprung feet from which the shaver head is deployed by a hydraulic cylinder. Travel per pass is approximately $1800 \mathrm{~mm}$. The shaver head is $300 \mathrm{~mm}$ wide and is designed for optimal removal depths of 1 to $10 \mathrm{~mm}$ per pass. Accuracy to within $0.1 \mathrm{~mm}$ shaving depth is achieved through depth removal control device.

The IVOD also has an online measuring system integrated into it. This will allow the operator to determine if sufficient material is being removed. The system consists of two large gas proportional detectors, onboard electronics, a computer display, and a computer data recording system.

\subsection{Demonstration Measurement and Observation}

Separate measurements and observations will be recorded for the shot blast and the contamination measuring systems. Observations will be recorded on data sheets, through written interviews, photographically, and on videotape.

\subsubsection{Mobilization}

The factors recorded during the mobilization of the equipment will include the following:

- The time required placing the equipment in operational condition, i.e., ready to start decontamination operations, once it is brought to the work area. The times will be rounded to the nearest quarter hour.

- The level of effort (LOE) and support staff required preparing the work area for using the cleaning and measuring system according to any required pre-approved procedures.

- Training of operators in the use and setup of the equipment.

- Assuring that utilities, electrical, and compressed air are present for the operation of the machine and the dust collection system. This should include preparation of connections between the supply and the machine.

- Preparation required for site paperwork including the Radiation Work Permit and training requirements.

- Training off-site personnel as required.

- Review of operating procedures supplied with the equipment to assure that they meet site requirements for safety and worker protection. 


\subsubsection{Operation}

The following quantitative and qualitative information will be recorded during shaving operations:

- The rate of concrete removal on smooth walls

- The relative performance on uneven and rough surfaces

- Closeness to floors, corners, and obstructions

- LOE required for operation of the equipment

- The ease of operation for the operator

- Setup time required when moving to a new area

- LOE required for confirmatory measurements to assure contamination has been removed

- Ease of characterization of the finish surface

- Speed of removal of miscellaneous metals embedded in the concrete, such as equipment mounting studs

- Use of the measuring system for control resulting in waste reduction

- Impact on nearby operations

- Noise level

- Airborne activity/dust loadings in work area

- Ease of access into corners and round obstructions

- Assessment of industrial safety.

\subsubsection{Maintenance}

The maintenance information recorded during the shaving operations using the equipment will include

- Time and LOE required for calibration of the measuring system

- Time and LOE related to maintaining the shaver

- Time and LOE required replacing the consumables in the waste collector

- Costs of consumables in all systems

- Time and LOE to make any unanticipated repairs

- LOE of support required during maintenance operations.

\subsubsection{Decontamination and Waste Handling}

The information recorded during equipment decontamination and waste handling will include

- Time and LOE required decontaminating equipment for release from the Rancho Seco site

- Time and LOE required packaging the waste generated during the decontamination process

- Cost of equipment/consumables disposed of as waste

- LOE of support required during decontamination and waste handling

- Method and cost for waste disposal. 


\subsubsection{Demobilization}

The information recorded during the equipment demobilization process will include

- The time required over and above decontamination operations to prepare the equipment for release from the site

- The LOE required to prepare the equipment for release from the site.

\subsection{Evaluation Criteria}

The demonstration will be deemed completed when the following criteria have been met:

- Production rates for level vertical surfaces have been determined and recorded.

- Production rates for uneven vertical surfaces have been determined and recorded.

- Online measurement systems data has been confirmed by standard monitoring techniques.

- Times and LOE have been determined for all operations beginning with mobilization and ending with demobilization.

- Costs for consumables have been determined.

- Time and LOE for all support staff have been recorded for all operations.

- Copies of the raw data have been supplied to all participants.

- Assessments have been made of radiological and conventional safety.

\subsection{Demonstration Schedule and Resource Requirements}

The overall schedule for the online measuring system demonstration is shown in Figure 2. The details of the actual demonstration schedule are presented in Section 3.1.

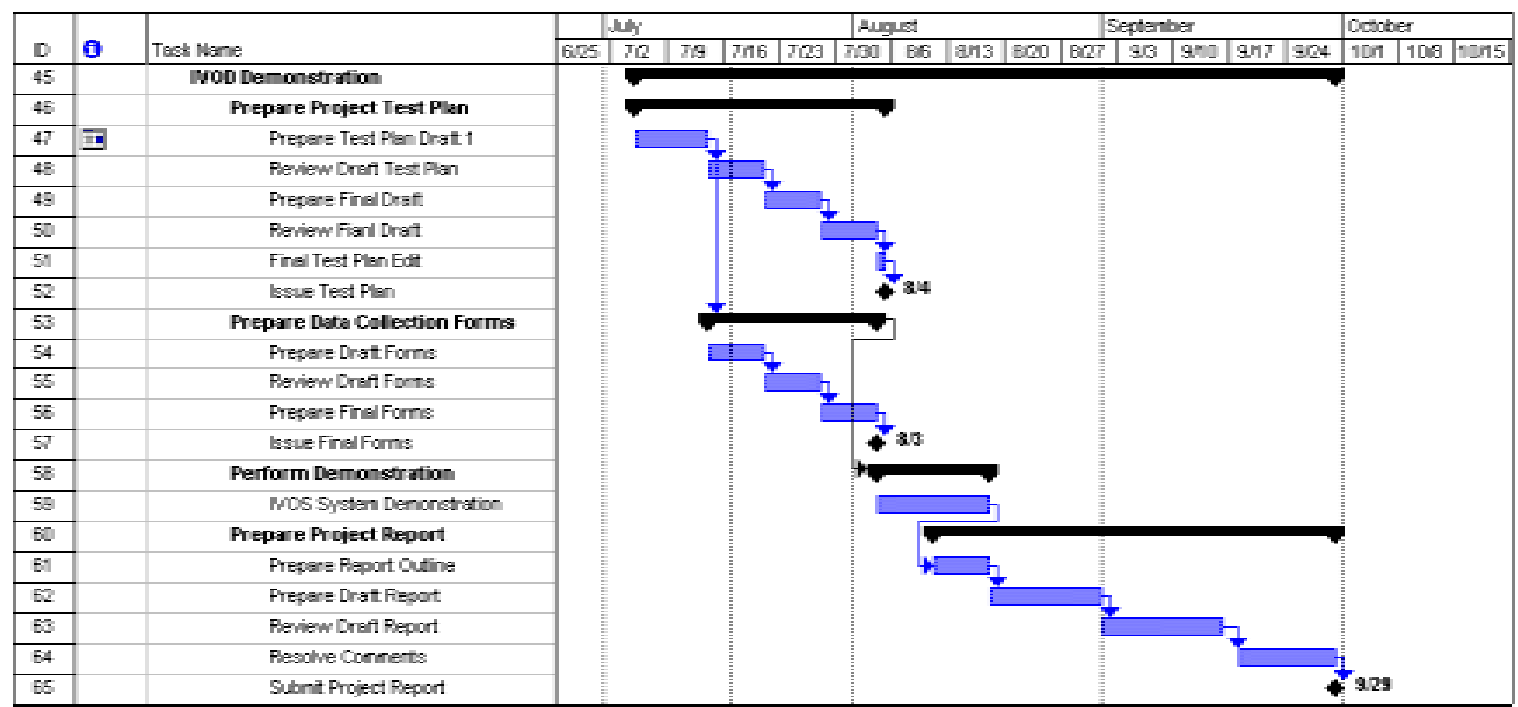

Figure 2. Schedule for the demonstration of the FIU IVOD system demonstration project at Rancho Seco. 


\subsection{Schedule}

The detailed schedule for the on-site portion of the demonstration is detailed in the following table. The schedule covers the four-week time period beginning Monday, May 1, 2000.

Table 2

Detailed on-site schedule of activities for the demonstration of the FIU-developed online Decontamination Measuring System

\begin{tabular}{|l|l|}
\hline Date & Operations \\
\hline $8 / 15 / 00$ & $\begin{array}{l}\text { Finalize details for the complete demonstration during the } \\
\text { week of August 21. }\end{array}$ \\
\hline $8 / 16 / 00$ & $\begin{array}{l}\text { Plant site orientation. } \\
\text { Mobilize the IVOD and measuring equipment for operation } \\
\text { and training of Rancho Seco personnel. }\end{array}$ \\
\hline $8 / 16-$ & $\begin{array}{l}\text { Train D\&D personnel to use the shot blast system and the } \\
\text { online measuring system. }\end{array}$ \\
\hline $8 / 21 / 00$ & $\begin{array}{l}\text { Mobilize equipment, set up for clean floor operations. } \\
\text { Perform wall-cleaning demonstration on uncontaminated } \\
\text { concrete. }\end{array}$ \\
\hline $8 / 22 / 00$ & $\begin{array}{l}\text { Perform wall-cleaning operations on contaminated wall } \\
\text { areas utilizing the online measuring system. }\end{array}$ \\
\hline $8 / 23 / 00$ & Decontaminate the equipment and prepare it for shipping. \\
\hline
\end{tabular}

\subsection{Resource Requirements TBD}

Equipment requirements include the following:

- Equipment - provided by FIU-HCET

$\bigcirc$ Online Measurement of Contamination - Floor Unit - 480 VAC 3 phase, $40 \mathrm{~A}$

- HAZVAC - Vacuum/waste collection Unit - 110 VAC Single phase, 20A

- Support Equipment - Provided by FIU-HCET

○ Diesel Powered Air Compressor 900 cfm, 110-125 psig

- Cooler and Dryer

- Miscellaneous - Provided by FIU-HCET

- HEPA filter, air hoses, vacuum hoses, roughing filters, steel shot (55-gal drum), diesel fuel, power cables, power cords, tool box and tools

- Equipment/Power Requirements - provided by SMUD

○ Forklift (5000 lbs.)

- Electrical power as indicated above

- Rad. Monitoring instruments

- Waste management

○ Decon Services

- Site-specific training 
Personnel requirements:

\begin{tabular}{|c|l|l|l|}
\hline No. of Employees & Type of employee & Type of Work & Equipment \\
\hline 2 FIU-HCET & Technicians & Operate equipment & Wall shaver \\
\hline 1 SMUD & RPT & $\begin{array}{l}\text { Radiation } \\
\text { Monitoring }\end{array}$ & $\begin{array}{l}\text { Hand-held } \\
\text { instruments }\end{array}$ \\
\hline 1 SMUD & Lead Engineer & Oversite & \\
\hline 1 SMUD & Fork Lift Operator & Fork Lift Operation & Fork Lift \\
\hline 2 FIU-HCET & Supervisor/trainers & $\begin{array}{l}\text { Trained D\&D labor } \\
\text { on the uses of the } \\
\text { decontamination and } \\
\text { characterization } \\
\text { units }\end{array}$ & \\
\hline
\end{tabular}

\subsection{Equipment Mobilization, Decontamination and Demobilization TBD}

\section{IVOD}

- Check cables and electrical connections for cuts and external wear.

- Check dust collection system, including hoses, for tight connections and wear.

- Check the incoming power supply to dust arrestor by pressing marked buttons start fan, compressor and pulse system.

- Press button to start fan motor. After a short period, a stand-by light (orange color) will light up.

- Check to make sure the side shields are in place.

- Press the blast motor start button. The main motor will start in two-speed stage.

- Press the drive button. The machine is operational.

- Commence blasting operations.

- Fill the abrasive hopper through the access lid, approximately $50 \mathrm{KG}$.

- Check that all electric motors are running in the correct direction.

- With both directional controls in the forward position, slowly turn the speed control switch clockwise. The machine will move forward.

- Pull the abrasive feed control lever upwards until the ammeter is reading 15-20 amps.

- To end the blasting operation, push down the lever controlling the abrasive feed to the Off position.

- Push the directional controls to the center (neutral) position.

- Stop the blast wheel motor by pressing the Red button.

- Press the Red button controlling the drive system to stop the drive system.

- Press the Red button to stop the exhaust fan.

- Press the Red button on the dust arrester to stop the pan, compressor, and pulse systems.

- Check the entire machine and dust collection system for contamination.

- Decontaminate as required.

- Remove the machine from the area. 


\section{Radiation Measuring System}

- Need operational steps for the radiation detection system.

\subsection{Disposition of Derived Waste}

Waste in the form of dust and metal particles is deposited directly by the dust collection system's filters and storage drum. The waste will also include contaminated filters, decontamination materials, and equipment parts that can not be decontaminated. Because of the extremely low levels of contamination, it is expected that the waste will be disposed of with other LSA waste. Rancho Seco staff will determine the specific disposition of all wastes generated during the demonstration.

\subsection{Data Collection Requirements}

The data collected during the demonstration process will include objective data such as times, amounts of waste material generated, number of workers, and also observation obtained from interviews with those working on and observing the equipment in action.

\subsection{Performance Data}

The data collected here will be related to the time and level of effort needed to perform the activities demonstrated. In addition, observations by those watching the demonstration and interviews with those participating will provide qualitative data. All will be included in the final reports.

\subsection{Cost Data}

Equipment costs and the cost of disposables will be tabulated. Specific cost data will not be presented since it is directly facility-dependent. However, the detailed level of effort data will allow costs to be easily derived. Waste volumes will also be tabulated so that disposal costs can be calculated.

\subsection{Photographic Data}

Photos of equipment, before and after photos of surfaces, and decontamination efforts will be made. Representative video will be made during the demonstration if possible.

\subsection{Training Requirements TBD}

FIU-HCET staff will train decontamination workers in the operation of the shaving and radiation measuring equipment. Rancho Seco employees will be required to sign a checklist verifying the training they have received. FIU-HCET staff will be under escort by Rancho Seco personnel.

\subsection{Procedures}

No new or additional procedures are anticipated. Equipment operation will be as specified in the vendor's manuals and other operations will use routine D\&D procedures. 


\subsection{Health and Safety}

No special health and safety requirements are anticipated. Routine D\&D procedures will apply and application-specific requirements. Safety glasses are required for operation of the grit blast equipment. 